\title{
Finite element analysis of high strength reinforced concrete beams
}

\author{
$C L \mathrm{Oh}^{1, *}, S W \mathrm{Lee}^{1}, M Z$ Mohd Raizamzamani ${ }^{1}, A R$ Azerai $^{1}$, and $Y$ Norrul Azmi ${ }^{1}$ \\ ${ }^{1}$ Faculty of Civil Engineering, Universiti Teknologi MARA Malaysia,40450 Shah Alam, Selangor, \\ Malaysia.
}

\begin{abstract}
Development of high strength concrete as a new ecological construction material to sustain the gradually expanding construction industry has arisen. This paper presents nonlinear finite element analysis of three-dimensional high strength reinforced concrete beams using ABAQUS. The uniaxial compressive strength for the beam models were taken from the existing experimatal data on high strength concrete cubes. Eurocode 2 was also used to establish material parameters for the constitutive models for concrete and reinforcing bars. In this study, two $150 \mathrm{~mm} \times 200 \mathrm{~mm} \times 1200 \mathrm{~mm}$ simply supported rectangular concrete beam models subjected to loads at different shear span to effective depth ratios $(a / d=1.0$ and 2.0$)$ were analysed. Numerical results were validated with the existing experimental data specifically on the load-deflection responses and von mises stresses. It was found that the finite element results show greater than $70 \%$ agreement with the experimental results.
\end{abstract}

\section{Introduction}

Owing to the growth of high-rise building and bridges construction, high strength concrete (HSC) has been widely investigated recently $[1,2]$. Research works on searching the most efficient, sustainable as well as economic methods to enhance the performance of HSC have been conducted. HSC generally shows better performance compared to conventional concrete. Properties of HSC such as good durability, high compressive and tensile strengths make the concrete as one of the popular innovation in the construction industry worldwide. There is no specific definition of HPC in Eurocode 2, however the different material properties of the concrete strength lower and greater than C50/60 may be one of the significant indication. Literatures on the high strength concrete can be found in $[3,4]$.

Investigation of the behaviours of green HSC structures through experimental works are generally costly compared to numerical analysis. Therefore, Finite Element (FE) analysis of the structure using good constitutive models could save the construction time and cost. Constitutive models based on elasticity, nonlinear-elasticity, plasticity, fracture mechanics, damage theories have been generally used to investigate the behaviour of concrete structures that subjected to various loadings [5]. Several models have been proposed in the investigation of plasticity failures. For instance, Druker-Prager yield criterion was employed in the study for shear design of reinforced concrete beams [6]. The capability of concrete damaged plasticity (CDP) model in modelling the ultra high performance fibre reinforced concrete beams was investigated [7]. The behaviour of steel-polypropylene 
hybrid fiber reinforced concrete column subjected to cyclic loading by using a modified concrete damaged plasticity model was simulated [8]. Mohr-Coulomb rupture criterion was used in the numerical investigation of double shear models considering both with and without a gap interface [9].

This paper presents nonlinear three-dimensional FE analysis of reinforced concrete beams using concrete damaged-plasticity (CDP) model available in the software ABAQUS [10]. The FE results are validated against the experimental data obtained in [11]. The experimental data was collected from four-point bending test on two RC beams with same dimensions and materials that subjected to loadings at different shear span over effective depth ratio.

The outline of the paper is as follows. In Section 2, material properties and constitutive models for concrete and steel bars are presented. In Section 3 describes both the experimental tests in [11] and numerical modelling of FE models. The numerical results such as load-displacement curves and von mises stresses are compared with the the experimental data in Section 4. The conclusions are addressed in Section 5.

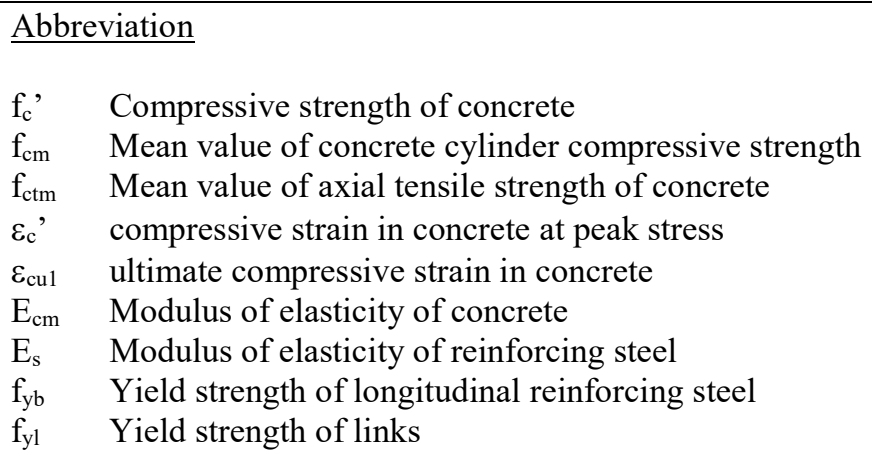

\section{Material Properties and Constitutive Models}

This section presents the material properties and constitutive models for concrete and reinforcing bars used in the study.

\subsection{Concrete}

Uniaxial compressive strength $f_{c}$ ' for the concrete based on experimental cube tests at 28 days is taken as $64.77 \mathrm{MPa}$. Other strength and deformation characteristics for concrete used for the models are suggested from Eurocode 2.

Modulus of elasticity of concrete is highly correlated to the compressive strength of concrete with quartzite aggregates and can be obtained by using the following expression:

$$
E_{c m}=22 \times 10^{3}\left[\left(f_{c m}\right) / 10\right\rceil^{0,3} \mathrm{MPa}
$$

where $f_{c m}$ is the mean value of concrete cylinder compressive strength. This mean strength is assumed to be the characteristic strength of cylinder compressive strength plus $8 \mathrm{MPa}$.

Owing to the availability of only the compressive strength of concrete from cube test, an equivalent cylinder compressive strength suggested by Eurocode 2 was used.

Poisson's ratio of 0.2 is taken for uncracked concrete. The mean value of axial tensile strength $f_{c t m}$ of concrete with grade $\mathrm{C} 50 / 60$ is calculated as 


$$
f_{c t m}=2.12 \cdot \operatorname{In}\left(1+\left(\frac{f_{c m}}{10}\right)\right) \mathrm{MPa}
$$

The compressive strain in concrete at peak stress $f_{c}$ is formulated as

$$
\varepsilon_{c}^{\prime}=\frac{0.7 f_{c m}^{0,31}}{100} \leq \frac{2,8}{100}
$$

whereas the ultimate compressive strain in concrete with cylinder compressive strength, $\varepsilon_{\mathrm{cu} 1}$ greater than $50 \mathrm{MPa}$ can be expressed as

$$
\varepsilon_{c u 1}=\frac{2.8+27\left[\left(98-f_{c m}\right) / 100\right]^{4}}{100}
$$

The following equation for the stress-strain curve proposed by Eurocode 2 was adopted for the concrete:

$$
\frac{\sigma_{c}}{f_{c m}}=\frac{k \eta-\eta^{2}}{1+(k-2) \eta} \mathrm{MPa}
$$

where

$$
\eta=\frac{\varepsilon_{c}}{\varepsilon_{c 1}}, \quad k=1.05 E_{c m} \times \frac{\left|\varepsilon_{c 1}\right|}{f_{c m}}
$$

This expression is valid for $0<\left|\varepsilon_{\mathrm{c}}\right|<\left|\varepsilon_{\mathrm{cu} 1}\right|$. The stress strain curve for concrete used in the study is shown in Figure 1(a).

\subsection{Reinforcing bars}

The beams were cast with top and bottom longitudinal reinforcing steel bars and horizontally spaced links. Yield strength for the longitudinal reinforcing steel bars $f_{\mathrm{yb}}$ and links $\mathrm{f}_{\mathrm{yl}}$ are $460 \mathrm{MPa}$ and $250 \mathrm{MPa}$, respectively. Modulus of elasticity for both reinforcing steel bars and link $\mathrm{E}_{\mathrm{s}}$ is $200 \mathrm{GPa}$. The steel bars were modelled as elastic perfectly plastic and the stress strain curve is proposed as shown in Figure 1(b).
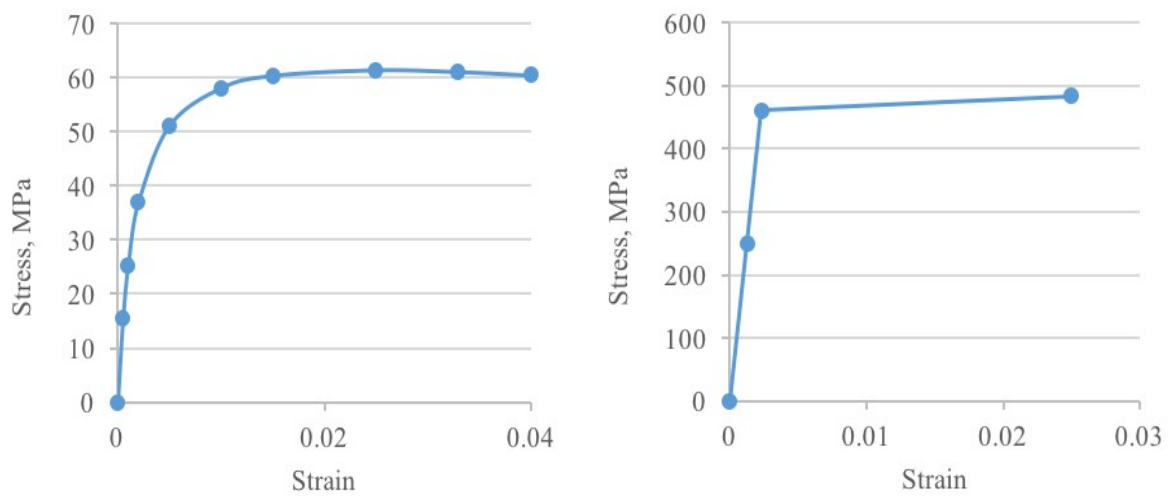

Fig. 1. Stress-strain curve for nonlinear analysis (a) concrete and (b) steel bars. 


\section{Methodology}

\subsection{Experimental corroboration}

Two high strength reinforced concrete beam specimens from series 'RB' of a past experimental research work were used in the study for model verification. The beam specimens with size of $150 \times 200 \times 1200 \mathrm{~mm}$ were tested under a four-point bending static load test. Two numbers of $10 \mathrm{~mm}$ diameter reinforcing bars with characteristic strength of $460 \mathrm{~N} / \mathrm{mm}^{2}$ used as top and bottom bars were placed with concrete cover $30 \mathrm{~mm}$. The stirrups of $6 \mathrm{~mm}$ diameter and characteristic strength of $250 \mathrm{~N} / \mathrm{mm}^{2}$ were fabricated with spacing at $200 \mathrm{~mm}$ centre to centre along the beam.

Each of the simply supported specimens were loaded to fail under the four-point bending static load test with different shear spans, $a$. The specimens RB1.0 and RB2.0 denote the beam specimens in series ' $R B$ ' which have a shear span to effective depth ratio $(a / d)$ of 1.0 and 2.0, respectively. Specifically, the corresponding shear spans for RB1.0 and RB2.0 are $160 \mathrm{~mm}$ and $320 \mathrm{~mm}$, respectively. The details of the experimental set-up is illustrated in Figure 2. The concrete mix composition as well as experimental results such as load deflection responds and the failure modes of the specimens can be found in Oh et al. (2013).

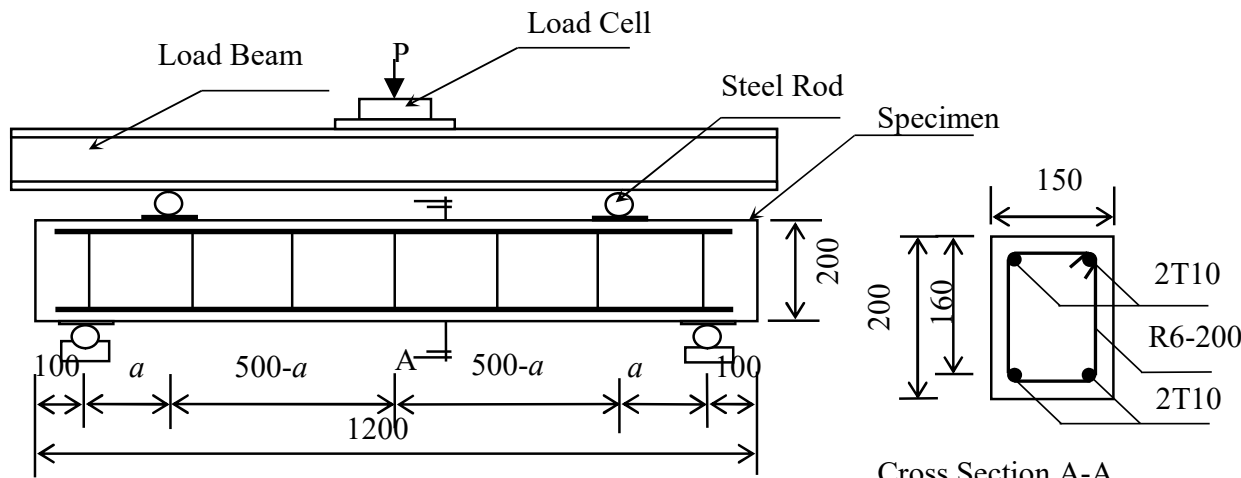

Fig. 2. Beam specimen details (Units: $\mathrm{mm}$ ) [11].

\subsection{Numerical Modeling}

Two reinforced concrete beam models with details as shown in Figure 2 were analysed using finite element software ABAQUS/Standard. The constitutive models for concrete and reinforcing bars used for the reinforced concrete beam models are discussed in Sections 2.1 and 2.2. Continuum elements specifically 8-node reduced integration brick elements (C3D8R) which are suitably for both linear and nonlinear analysis were used to model the concrete (Figure 3a). The reinforcing bars and stirrups were modeled as 3D truss elements (T3D2) which transmit only axial load (Figure 3b). Full bond between reinforcing bars, stirrups and concrete was assumed by using tie constraints. Pinned supports were assumed at $100 \mathrm{~mm}$ measured from both edges of the beam (Figure 3c). In order to simulate the four-point bending test, two point loadings were imposed on the beams. The locations of the two point loadings for the three beam models were differentiated by a/d ratio, particularly 1.0 and 2.0. The displacement at midspan exceeding $50 \mathrm{~mm}$ was set as the termination criteria. 


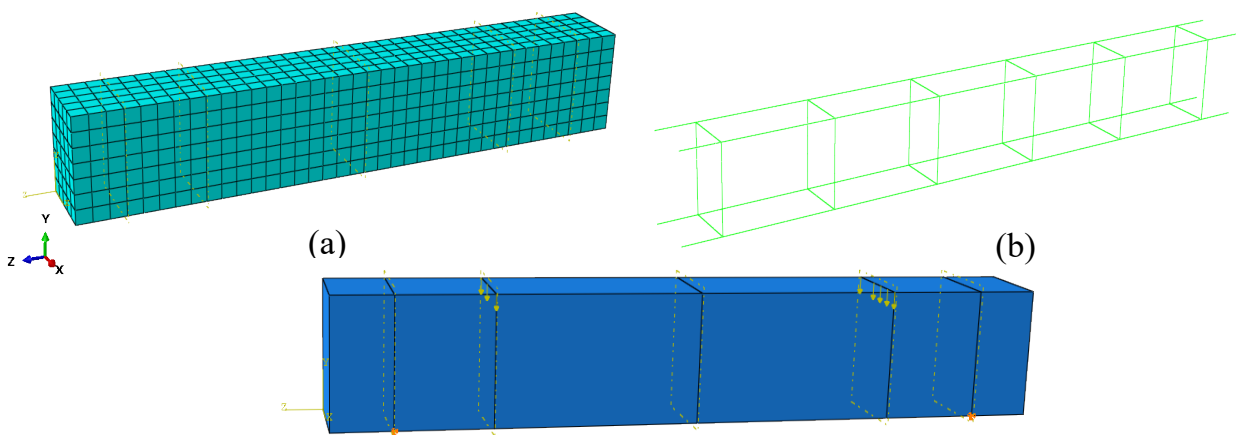

(c)

Fig. 3. Three-dimensional reinforced concrete beam models (a) mesh for concrete beam, (b) reinforcing bars and stirrups and (c) loadings and supports.

\section{Verification of FE Models}

\subsection{Load and Displacement Curves}

Figure $4 \mathrm{a}$ and $4 \mathrm{~b}$ presents the load to midspan deflection curves from both FE analysis and experimental testing for beams RB1.0 and RB2.0, respectively. It could be observed from load displacement curves for both beam RB1.0 and RB2.0, the curves from FE results are stiffer at the linear region. It could be seen also that the FE results has good agreement with the experimental results at linear region. After the first crack, the load displacement curve of FE results has slight divergence from experimental results. This indicates that the constitutive models used for concrete and reinforcing bars particularly at plastic region need to be improved such to simulate the behavior of the beams appropriately.

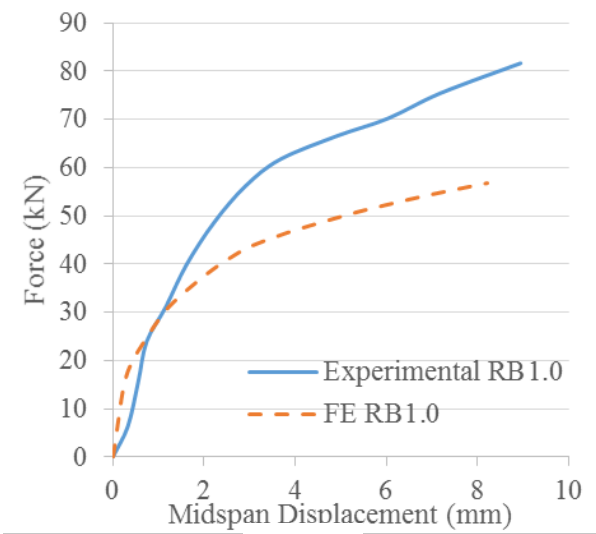

(a)

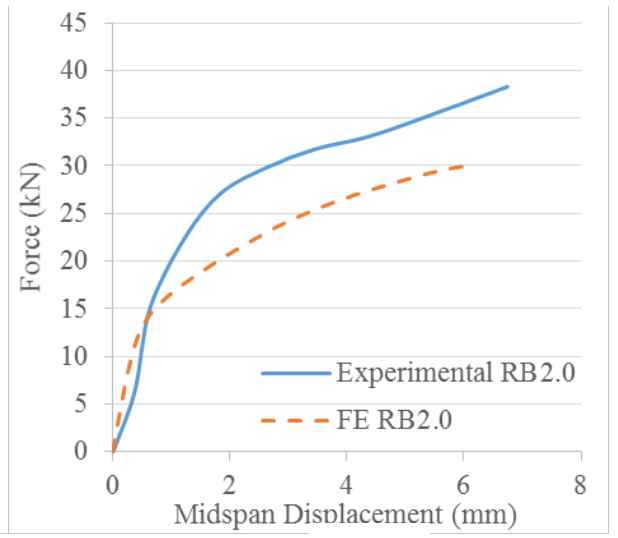

(b)

Fig. 4. Load and displacement curves (a) Beam RB1.0 and (b) Beam RB2.0.

Table 1 summarizes the first crack load and maximum load of the beams for both FE and experimental results. The mean ratios of numerical-to-experimental first cracking load and ultimate load of 0.87 and 0.76 , respectively. 
Table 1. Comparison of FE and experimental first crack load and maximum load.

\begin{tabular}{ccccccc}
\hline Beam & \multicolumn{2}{c}{ First crack load, $\mathrm{P}_{\text {cr }}$} & \multicolumn{2}{c}{$\begin{array}{c}\text { Maximum Load, } \mathrm{P}_{\max } \\
(\mathrm{kN})\end{array}$} & \multicolumn{2}{c}{ FE/Exp } \\
\hline & $\mathrm{FE}$ & Exp & FE & Exp & $\mathrm{P}_{\text {cr }}$ & $\mathrm{P}_{\max }$ \\
\hline RB1.0 & 20 & 25 & 58 & 80 & 0.800 & 0.725 \\
\hline RB2.0 & 14 & 15 & 30 & 38 & 0.933 & 0.789 \\
\hline
\end{tabular}

\subsection{Failure modes}

Figure $5 \mathrm{a}$ and $5 \mathrm{~b}$ presents the von mises stress for beam models RB1.0 and RB2.0, respectively. High von mises stress is used to indicate the failure modes in the beams. It could be seen from both models, high von mises stresses occurs at the locations of loads and supports. At the location of loads, crushing of concrete is expected from the models, and the results has good agreement with experimental results (Figure 6). Both beam models demonstrates higher stress in a form of diagonal struts but with different angles $\phi$. Besides, there is higher stress at the midspan of bottom beam model RB2.0 compared to RB1.0. Uniform flexural cracks at the same location could be found from the experimental results in RB 2.0.

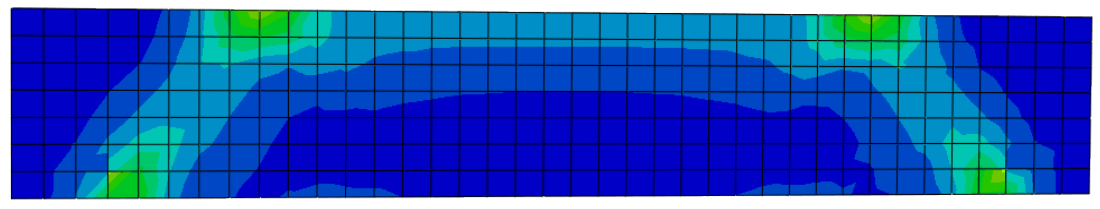

(a)

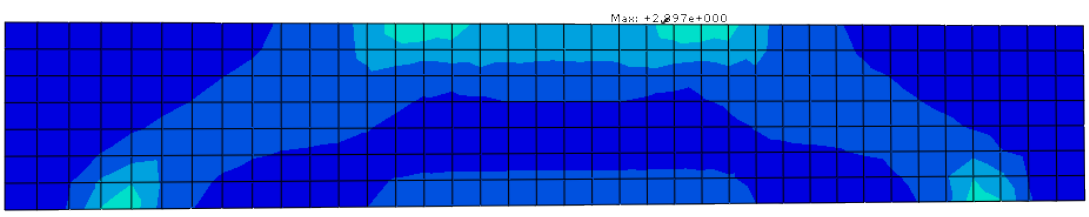

(b)

Fig. 5. Von misses stress (a) RB1.0 and (b) RB2.0.
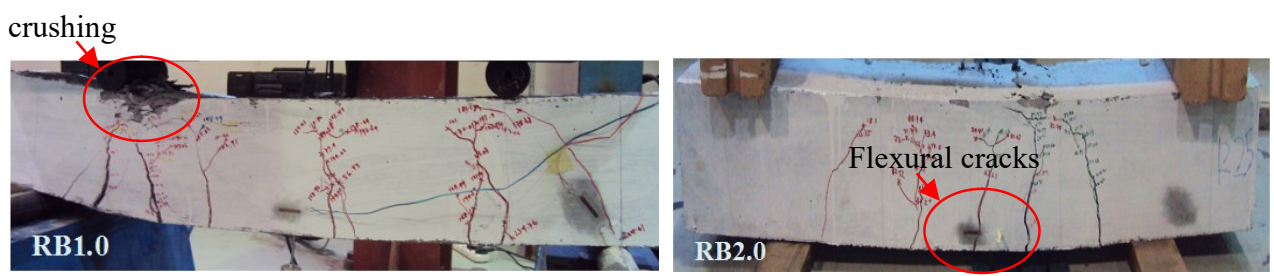

Fig. 6. Crack patterns for RB1.0 and RB2.0. 


\section{Conclusions}

This paper presents nonlinear finite element analysis of three-dimensional high strength reinforced concrete beams containing waste. The finite element results show greater than $70 \%$ agreement with the experimental results. The behaviour of the beams is influenced by the a/d ratio which could be demonstrated through experimental results and numerical analysis. The ultimate load increase with lesser a/d ratio. There is obvious difference in the stress distribution when the a/d ratio change.

Authors wishing to acknowledge assistance or encouragement from Faculty of Civil Engineering, Universiti Teknologi Mara Shah Alam.

\section{References}

1. Z. Wu, K. H. Khayat, and C. Shi, "Effect of nano-SiO 2 particles and curing time on development of fiber-matrix bond properties and microstructure of ultra-high strength concrete," Cement and Concrete Research, vol. 95, pp. 247-256, 2017.

2. B.-I. Bae, J.-H. Chung, H.-K. Choi, H.-S. Jung, and C.-S. Choi, "Experimental study on the cyclic behavior of steel fiber reinforced high strength concrete columns and evaluation of shear strength," Engineering Structures, vol. 157, pp. 250-267, 2018.

3. P. Nath, P. K. Sarker, and W. K. Biswas, "Effect of fly ash on the service life, carbon footprint and embodied energy of high strength concrete in the marine environment," Energy and Buildings, vol. 158, pp. 1694-1702, 2018.

4. S. Fallah and M. Nematzadeh, "Mechanical properties and durability of high-strength concrete containing macro-polymeric and polypropylene fibers with nano-silica and silica fume," Construction and Building Materials, vol. 132, pp. 170-187, 2017.

5. A. Earij, G. Alfano, K. Cashell, and X. Zhou, "Nonlinear three-dimensional finiteelement modelling of reinforced-concrete beams: Computational challenges and experimental validation," Engineering Failure Analysis, vol. 82, pp. 92-115, 2017.

6. G. Arslan, "Sensitivity study of the Drucker-Prager modeling parameters in the prediction of the nonlinear response of reinforced concrete structures," Materials \& design, vol. 28, no. 10, pp. 2596-2603, 2007.

7. M. Singh, A. Sheikh, M. M. Ali, P. Visintin, and M. Griffith, "Experimental and numerical study of the flexural behaviour of ultra-high performance fibre reinforced concrete beams," Construction and Building Materials, vol. 138, pp. 12-25, 2017.

8. Y. Chi, M. Yu, L. Huang, and L. Xu, "Finite element modeling of steel-polypropylene hybrid fiber reinforced concrete using modified concrete damaged plasticity," Engineering Structures, vol. 148, pp. 23-35, 2017.

9. H. C. Biscaia, C. Chastre, and M. A. Silva, "Modelling GFRP-to-concrete joints with interface finite elements with rupture based on the Mohr-Coulomb criterion," Construction and Building Materials, vol. 47, pp. 261-273, 2013.

10. Hibbitt, Karlsson, and Sorensen, ABAQUS/Explicit: user's manual. Hibbitt, Karlsson and Sorenson Incorporated, 2001.

11. C. L. Oh, S. W. Lee, M. A. a. Masrom, and C. H. Goh, "Experimental Study on Shear Behaviour of High Strength Reinforced Recycled Concrete Beam," Pertanika Journal of Science and Technology, vol. 21, no. 2, pp. 601-610, 2013. 